\title{
Quantifying freshwater-induced fragmentation of submerged aquatic vegetation communities using a multi-scale landscape ecology approach
}

\author{
Rolando O. Santos ${ }^{1, *}$, Diego Lirman ${ }^{1}$, Joseph E. Serafy ${ }^{1,2}$ \\ ${ }^{1}$ Rosenstiel School of Marine and Atmospheric Science, University of Miami, 4600 Rickenbacker Causeway, Miami, \\ Florida 33149, USA \\ ${ }^{2}$ NOAA, National Marine Fisheries Service, Southeast Fisheries Science Center, 75 Virginia Beach Drive, Miami, \\ Florida 33149, USA
}

\begin{abstract}
Species composition and abundance of nearshore submerged aquatic vegetation (SAV) of Biscayne Bay, Florida, USA, are influenced by pulsed delivery of fresh water from canals that drain the Everglades and adjacent urban and agricultural areas. In the present study, we evaluated whether freshwater inflows were correlated with the spatial structure (e.g. patchiness, fragmentation, spatial heterogeneity) of SAV. SAV patches were delineated using aerial photographs and object-based classification, and the SAV seascape structure was characterized at different spatial scales (200 $\mathrm{m}$ to $1 \mathrm{~km}$ from shore) using landscape metrics. The area closest to shore (200 $\mathrm{m}$ buffer) was identified as the area with the highest heterogeneity in SAV seascape structure; areas beyond this buffer did not differ significantly in landscape metrics. Within the $200 \mathrm{~m}$ buffer, SAV seascapes clustered into continuous SAV structures (CSS) and fragmented SAV structures (FSS). CSS had a higher proportion of the benthos covered by larger SAV patches with simpler boundaries. FSS had a higher density of smaller SAV patches with complex shapes and a lower proportion of the substrate covered by SAV patches. Neither structure type was distributed randomly along the shoreline. CSS were prevalent in areas with high and stable salinity. FSS were prevalent in areas influenced by freshwater discharges where salinity is low and variable, highlighting how the pulsed release of fresh water may adversely influence the structure of SAV seascapes, potentially resulting in fragmentation of the benthic community. Thus, this seascape approach provides a tool to assess the influences and effectiveness of the Everglades Restoration Project in Biscayne Bay.
\end{abstract}

KEY WORDS: Submerged aquatic vegetation · Seagrass · Landscape ecology · Seascape structure · Salinity patterns $\cdot$ Water-quality influences $\cdot$ Habitat fragmentation $\cdot$ Everglades restoration

\section{INTRODUCTION}

Submerged aquatic vegetation (SAV) communities provide key ecological services such as organic carbon production and export, nutrient cycling, sediment stabilization, enhanced biodiversity, and trophic transfers to adjacent habitats in tropical and temperate regions (Orth et al. 2006). Significant patterns of decline and shifts in community structure have been documented for these communities worldwide (Duarte 2002, Waycott et al. 2009). Among the main causes of this decline are chemical pollution, eutrophication, physical impacts, and trophic-structure modifications (Duarte 2002, Orth et al. 2006). Associated with declines in SAV biomass are losses in the habitat value that these ecosystem engineers provide as essential refuges and as sources of nutrition to a large number of resident and transient macrofaunal organisms (Costanza et al. 1997, Orth et al. 2006).

Perturbations to SAV communities are most commonly quantified at fine spatial resolution by in situ observations and descriptions of SAV shoot/ramet den- 
sity or percent cover (Waycott et al. 2009). Comparatively, methodologies that consider processes occurring over larger spatial scales are rarely considered (Robbins \& Bell 1994, Kendall 2005, Mellin et al. 2009). Nevertheless, large-scale spatial SAV habitat patterns (e.g. habitat size, fragmentation, arrangement) can influence ecological patterns and processes such as faunal recruitment, dispersal, survivorship, and connectivity (Pittman et al. 2004, 2007, Mellin et al. 2007, Hovel \& Regan 2008), highlighting the need to evaluate the role of disturbances on the structuring of largescale SAV spatial patterns. Concepts and analytical techniques developed in terrestrial landscape ecology provide a framework that can be readily adapted to assess large-scale SAV patterns and disturbance impacts. A landscape generally refers to a heterogeneous area composed of locally interacting ecosystems made up of homogenous units called habitat patches (GroberDunsmore et al. 2008). Adapting this term to marine systems, a SAV seascape can be considered as a heterogeneous mosaic of SAV patch habitats across a broad homogenous matrix (e.g. sand, mud, hard substrate). Thus, approaches developed in landscape ecology are ideal for quantifying spatial patterns of SAV patches because of the natural tendency of these communities to form variable-sized patches (Boström et al. 2006, Connolly \& Hindell 2006). In the present study, we utilized landscape metrics (referred to as spatial pattern metrics hereafter) to quantify the composition (e.g. diversity and abundance of patches) and configuration (e.g. spatial arrangement, position, orientation, size-frequency) of SAV patches across the seascape within Biscayne Bay, Florida, USA, a shallow subtropical lagoon that is heavily influenced by human activities including water management (Lirman et al. 2008a,b).

Tropical and subtropical marine ecosystems such as coral reefs, mangroves, and SAV patches are ecologically interconnected through the movement of fish and invertebrate species as well as inorganic and organic nutrients (Parrish 1989, Beck et al. 2001, Beets et al. 2003, Nagelkerken \& van der Velde 2004a,b, Orth et al. 2006, Davis et al. 2009). Habitat composition and configuration across the seascape are known to influence connectivity patterns among habitats (Pittman et al. 2007), and several studies have shown that species abundance and diversity are directly related to habitat heterogeneity (Nagelkerken et al. 2001, Jelbart et al. 2007). A heterogeneous seascape may support high species diversity by enhancing recruitment opportunities, providing a wide range of resource types (e.g. food items, space use for attachment or shelter), and influencing the outcome of biological interactions such as competition, predation, and foraging behavior (Parrish 1989, Irlandi \& Crawford 1997). Thus, impacts of water quality on the structure of SAV communities within the seascape can have significant cascading effects on higher trophic levels.

Previous research in Biscayne Bay has shown that abundance and species composition of SAV are directly related to salinity patterns, with areas containing low and highly variable salinity (i.e. adjacent to canals that discharge fresh water into littoral areas) exhibiting lower SAV species abundance and high variability in percent cover within patches (Lirman et al. 2008a,b, Lirman \& Serafy 2008). While response patterns to salinity have been documented at the within-patch scale, it is expected that spatial pattern metrics such as mean patch size, shape complexity, and patch density will also capture spatial heterogeneity of SAV, as species-specific responses may cascade to the seascape level and translate into differences in the composition (e.g. total area, percent cover by patch type) and configuration (e.g. size, patch density, patch shape, patch complexity) of the SAV seascape. In this study, we evaluated, for the first time, the potential influence of freshwater inflow on the structure of SAV communities in a coastal subtropical lagoon with a landscape approach commonly used to evaluate structural attributes of terrestrial landscapes. We hypothesized that (1) SAV seascape structure would be significantly different in areas with distinct salinity patterns; (2) higher SAV fragmentation would be observed in areas with extreme salinity values and high salinity variability; and (3) the influence of freshwater deliveries (and salinity) on SAV spatial pattern metrics would be concentrated on the habitats closest to shore where salinity patterns are more dynamic.

\section{MATERIALS AND METHODS}

Study area. The study area for this project was located in western Biscayne Bay, Florida, USA (Fig. 1). Biscayne Bay is a shallow subtropical lagoon located adjacent to the city of Miami and downstream of the Florida Everglades system. The hydrology of the Everglades has been severely modified over the last $100 \mathrm{yr}$ by the construction of a massive water management system that has altered the quantity, quality, and delivery of fresh water into the coastal bays (Davis \& Ogden 1994, Browder \& Ogden 1999). Historical hydrologic patterns that were dominated by sheetflow across the landscape have been replaced by canals as the main method of delivery of fresh water into the littoral habitats of Biscayne Bay. Areas where pulsed canal discharges take place experience drastic fluctuations in salinity over short periods, especially in the wet season (July to September) when water is released in pulses into coastal bays, mostly for flood management. 


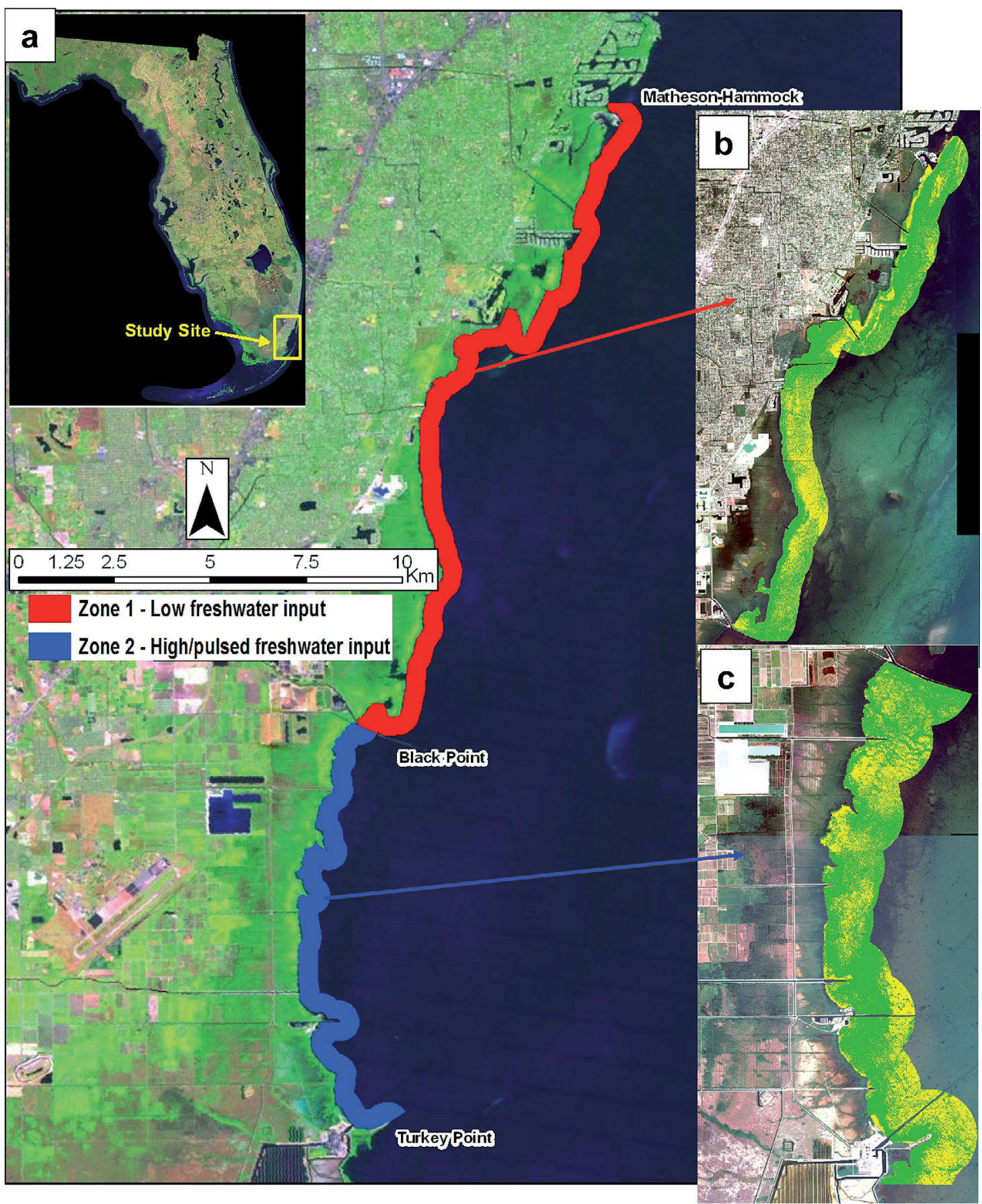

Fig. 1. (a) Study area in Florida, USA, with the delineation of the salinity zones, and the submerged aquatic vegetation (SAV) thematic map for (b) Zone 1 and (c) Zone 2. SAV dominant patches appear in green and SAV sparse patches in yellow. Thematic maps are drawn to different scales

Salinity patterns in Biscayne Bay are controlled by precipitation, freshwater runoff, canal flows, groundwater, and tidal oceanic influx that create distinct spatial and temporal patterns of salinity (Alleman 1995, Wang et al. 2003, Lirman et al. 2008a, b; South Florida Water Management District: www.sfwmd.gov/portal/ page/portal/pg_grp_sfwmd_watershed/biscayne_bay_ minimum375/tab744033?project=1303\&ou=440). Habitats with low and variable salinity are found along the western margin due to the influence of canals as well as overland and groundwater sources (Caccia \& Boyer 2005, Stalker et al. 2009). The present study concentrated on nearshore habitats $(<1 \mathrm{~km}$ from shore) bordered by fringing mangrove habitats. The study region 
was divided into 2 major zones that encompassed a total area of $38.9 \mathrm{~km}^{2}$ (Fig. 1). Zone $1\left(21.8 \mathrm{~km}^{2}\right.$ ) extended from Matheson Hammock to north of Black Point, and Zone $2\left(17.1 \mathrm{~km}^{2}\right)$ extended from south of Black Point to Turkey Point (Fig. 1). These zones were delineated based on distinct salinity regimes as previously described by Caccia \& Boyer (2005) and Lirman et al. (2008a,b). Zone 1, an area with limited input of fresh water from canal structures, is characterized by higher and more stable salinity patterns. In contrast, Zone 2 is significantly influenced by pulsed freshwater inflows from canals that create a nearshore environment with low and highly variable salinity.

Nearshore benthic habitats of Biscayne Bay are dominated by SAV communities composed of seagrasses and macroalgae (Zieman et al. 1989, Lirman et al. 2008a). These SAV communities, as well as the fringing mangrove shorelines, provide habitat for a large number of commercial and recreational fishery species such as pink shrimp (Diaz 2001), gray snapper, hogfish, and spotted seatrout (Serafy et al. 1997, 2003, Faunce et al. 2002).

Delineation of SAV patches and construction of thematic habitat maps. High-resolution $(0.3 \times 0.3 \mathrm{~m}$ pixel size) aerial photographs taken in May 2005 and provided by the Florida Fish and Wildlife Conservation Commission and Fish and Wildlife Research Institute were used to delineate different classes of SAV patches. The images were processed using ArcGIS v9.3 (ESRI) and ENVI v4.5 (ITT Visual Information Solutions) as follows: (1) the shoreline was delineated and digitized with a vector line, followed by the creation of a $1 \mathrm{~km}$ buffer, (2) the aerial photographs were re-sampled from $0.3 \mathrm{~m}$ resolution to $1 \mathrm{~m}$ resolution to provide more efficient processing and mapping results; and (3) the $1 \mathrm{~km}$ buffer and the re-sampled images were combined to delimit the desired area of study (i.e. nearshore SAV habitats).

An object-based supervised classification was performed with the ENVI v4.5 Feature Extraction module (ITT Visual Information Solutions: www.ittvis.com/ ProductServices/ENVI/Tutorials.aspx) to delineate and classify SAV patches and to create a thematic SAV map. The object-based image classification used here optimized the delineation of exterior and internal (patch internal discontinuities) SAV patch boundaries and provided better discrimination between SAV classes under varying water depth and image quality than per-pixel based image classification methods. Since objects (i.e. image segments with distinct homogenous spatial, textural, and spectral characteristics) are used instead of individual pixels, results do not have 'salt and pepper' effects or erroneously classified pixels across the image (Kelly \& Tuxen 2009). Also, the segmentation of the images into objects with distinct properties (e.g. tone, color contrast, texture, shape) helped distinguish the borders between different classes. The minimum patch size delineated by the Feature Extraction procedure was $100 \mathrm{~m}^{2}$.

Due to the optical limitations of the aerial photographs used (e.g. high variance of sun glint and color contrast, limited spectral information), the objectbased classification was limited to $2 \mathrm{SAV}$ patch classes: (1) SAV dominant (patches with $>30 \%$ SAV cover); and (2) SAV sparse (patches with $\leq 30 \%$ SAV cover). This classification scheme (i.e. SAV sparse and SAV dominant) was based on groupings of SAV samples that were identified by adapting the approach described by Mumby \& Harbourne (1999). The benthic data used for this classification were obtained from field surveys conducted in March to May 2005 using the Shallow Water Positioning System (SWaPS), a boat-based platform that collects geo-tagged images of the bottom (Lirman et al. 2008a). The high-resolution (10 MP) images of the bottom collected by SWaPS were analyzed on the computer screen to determine the percent cover of each SAV taxon. The percent cover of the different taxa from each site surveyed ( $\mathrm{n}=153$ sites) was examined in an agglomerative cluster analysis based on a resemblance matrix of Bray-Curtis similarities. Clusters with $50 \%$ similarity were identified, and used in a 'similarity percentages' (SIMPER) routine in PRIMER v6 (Clarke \& Warwick 2001), which decomposes average Bray-Curtis dissimilarities between all pairs of clusters. The SIMPER analysis identified threshold cover values of $30 \%$ as the main feature responsible for splitting sites into 2 robust groups (SAV dominant and SAV sparse).

Although remote sensing by aerial photographs has proven to be efficient and accurate in this study, aerial photographs provide limited taxonomic resolution for benthic classification. Thus, in this study, patches composed of macroalgae were not distinguished from patches of similar cover, but dominated by seagrasses. The lack of taxonomic resolution restricts our results and conclusions to broad categories (SAV sparse and SAV dominant). The use of aerial images has also increased the potential for omission (e.g. classes not assigned in the thematic map, but identified in the reference data) and commission errors (e.g. class assigned in the thematic map, but not in the reference data) in our analyses. Overall, the SAV sparse class was subject to high values of omission errors possibly caused by the inability to distinguish spectrally barren areas with organic sediments and high detritus cover versus areas with sparse SAV. Therefore, some of the barren areas with organic sediments and high detritus cover were classified as SAV dominant. In addition, commission errors could be caused by the similarity of spectral features among barren areas, areas with sparse SAV, and areas with high cover of drift algae. 
Drift algae tended to show optical characteristics similar to light-brown sediments and senescent SAV material. Future studies with multispectral imagery would be required for the documentation of taxa-specific patterns in structural metrics and to limit the occurrence of omission and commission errors.

Groundtruthing methods. A subset of the georeferenced benthic images obtained in 2005 was randomly selected (100 images per zone) as groundtruth points for the accuracy assessment of the classified thematic map. The value of SAV cover estimated for each image (values for macroalgae and seagrasses were added together to obtain a single aggregate SAV value) was compared to the value obtained for the same location extracted from the classified map. Accuracy was calculated as the proportion of images that matched the SAV class extracted from the thematic map. Using a confusion matrix, the SAV dominant class showed higher user accuracy (81\% in Zone 1, $80 \%$ in Zone 2) than SAV sparse (47\% in Zone 1, $55 \%$ in Zone 2). Since the user accuracy is a measure of the reliability of class in a thematic map, only the SAV dominant class was considered for further statistical analyses (e.g. spatial patterns of SAV seascape structures).

Multi-scale SAV seascape characterization. Following the mapping process, a group of circular extraction buffers was created around a set of 45 randomly

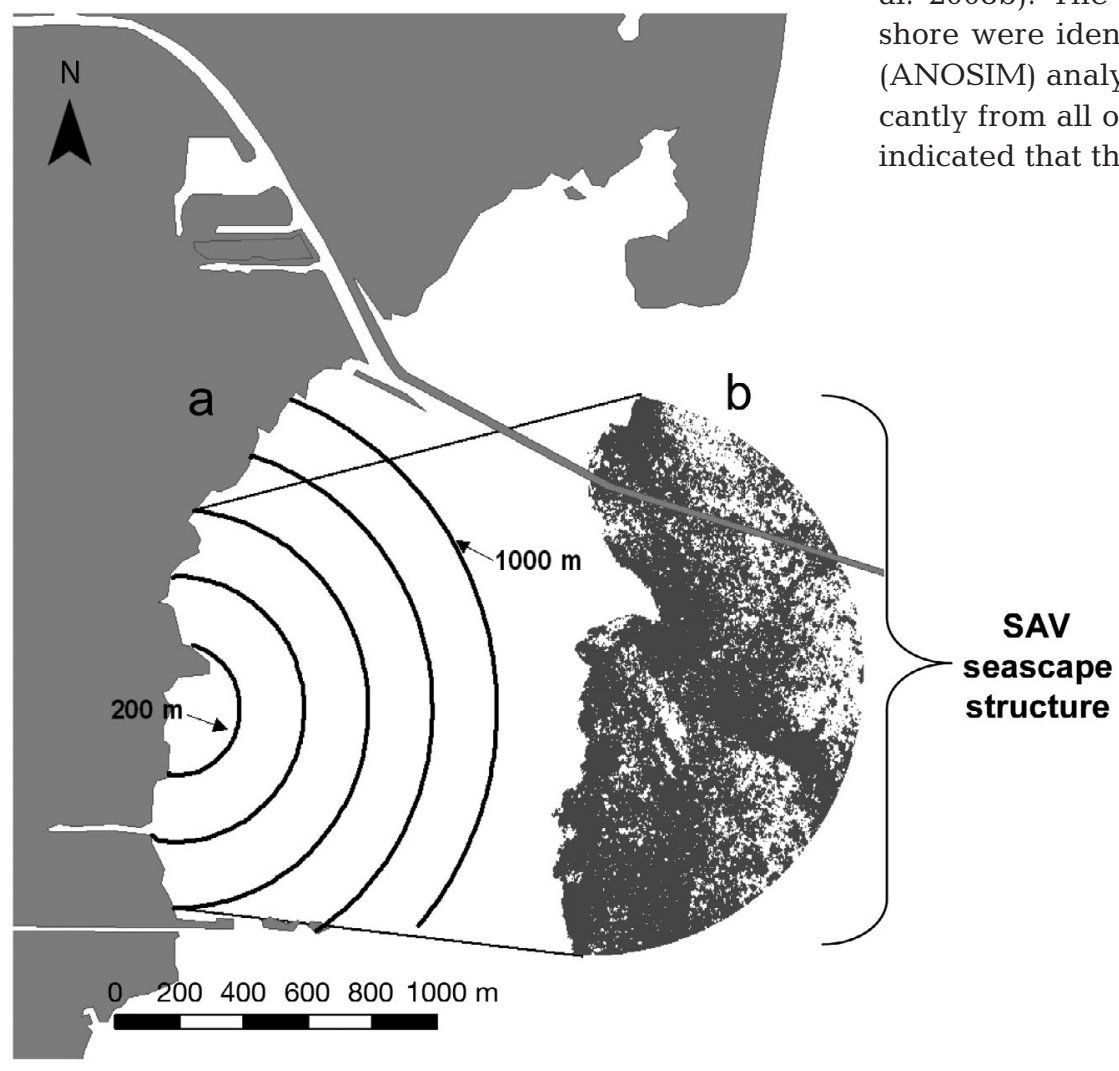

selected points along the shoreline of Zones 1 and 2 (Fig. 2a). These points served as the centers of the extraction buffers used to clip and obtain the delineated SAV patches within areas at increasing distances (i.e. scale) from shore. The buffers delineated were analyzed to establish the spatial scale at which the SAV seascape structures (described below) showed the highest heterogeneity (i.e. differences in spatial pattern metrics) within nearshore habitats (Fig. 2b).

The process of extracting the spatial pattern metrics from each buffer was automated using ArcGIS ModelBuilder (www.esri.com). In total, 4 metrics were extracted to quantify the SAV seascape composition or configuration at the class level (SAV dominant and SAV sparse) based on metrics calculated with Patch Analyst v4 and FRAGSTAT (McGarigal et al. 2002, Rempel 2008). These spatial pattern metrics were percentage of the landscape occupied by a given class (ZLAND), fractal dimension of patches (DLFD), mean patch size (MPS), and patch density (PDENS; Table 1). Mean patch size, shape complexity, and patch density (number) have been used in landscape ecology studies to assess the fragmentation dynamics of terrestrial habitats (Trzcinski et al. 1999, Turner et al. 2001, Botequilha et al. 2006).

In a preliminary analysis, $100 \mathrm{~m}$ extraction buffers were used $(100 \mathrm{~m}$ is the extension of the buffers used as strata in the benthic surveys conducted by Lirman et al. 2008b). The 2 buffers (100 and $200 \mathrm{~m}$ ) closest to shore were identified using an analysis of similarities (ANOSIM) analysis as the buffers that differed significantly from all other buffers. However, a pairwise test indicated that the 100 and $200 \mathrm{~m}$ buffers did not differ
Fig. 2. Illustration of the multi-scale seascape approach. The multi-scale seascape approach was composed of (a) extraction buffers with radius from $200 \mathrm{~m}$ to $1 \mathrm{~km}$ from shore used to extract the submerged aquatic vegetation (SAV) seascape at different scales, and (b) the characterization and definition of SAV seascape structure within each extraction buffer (i.e. scale) based on spatial pattern metrics: proportion of the landscape (ZLAND), mean patch size (MPS), double log fractal dimension (DLFD; shape complexity), and patch density (PDENS) 
Table 1. Spatial pattern metrics calculated based on McGarigal et al. (2002). There are 2 types of general categories: metrics that calculate composition and metrics that calculate configuration. Within these categories, the metrics are classified based on the aspect of the landscape pattern measured

\begin{tabular}{|c|c|c|c|c|}
\hline Metric & Code & Category & Aspect & Description \\
\hline $\begin{array}{l}\text { Percentage of } \\
\text { landscape }\end{array}$ & ZLAND & Composition & Area/density & $\begin{array}{l}\text { Percentage of the total landscape made up of the } \\
\text { corresponding class }\end{array}$ \\
\hline $\begin{array}{l}\text { Double log fractal } \\
\text { dimension }\end{array}$ & DLFD & Configuration & Shape & $\begin{array}{l}\text { Measure of patch perimeter complexity } \\
\text { Values range from } 1 \text { (simple form) to } 2 \text { (more complex form) }\end{array}$ \\
\hline Mean patch size & MPS & Configuration & Area/density & $\begin{array}{l}\text { Average size of a particular class } \\
\text { Units: ha }\end{array}$ \\
\hline Patch density & PDENS & Configuration & Area/density & $\begin{array}{l}\text { Number of patches of a certain class divided by the total } \\
\text { landscape area } \\
\text { Units: patches ha }{ }^{-1}\end{array}$ \\
\hline
\end{tabular}

from each other. Based on this, a $200 \mathrm{~m}$ radial increment was chosen for all further analyses. Thus, the radius of the extracting buffers around each site increased from $200 \mathrm{~m}$ to $1 \mathrm{~km}$ at increments of $200 \mathrm{~m}$. Therefore, each sampling site ( $\mathrm{n}=45$ sites) had 5 buffers, yielding a total of 225 extraction buffers.

Statistical analyses. All descriptive statistics were generated with SPSS v17.0. The spatial pattern metrics were $\log _{10}(x+1)$ transformed. Multivariate tests were run with PRIMER v6 (Clarke \& Warwick 2001) to analyze for differences in the SAV seascape structures among buffers and zones. To test differences in SAV seascape structures between treatments (i.e. buffers, zones) a 1-way ANOSIM was performed on the Euclidean distance similarity matrix of the spatial pattern metrics (Clarke \& Warwick 2001). The scale (i.e. buffer extension) with distinct SAV seascape structures was identified using the 1-way ANOSIM pairwise tests, and a combination of a simple agglomerative hierarchical clustering (CLUSTER, PRIMER) and non-metric multidimensional scaling (MDS) plots with buffer size as the main treatment (Clarke \& Gorley 2006). These tests were used to identify the buffer extension in which spatial pattern metrics were significantly dissimilar from the rest of the buffer extensions considered. A subsequent cluster analysis of sites at the selected scale was performed to identify groups with distinct SAV seascape structures. A series of similarity profile permutation tests (SIMPROF, PRIMER) were incorporated into the CLUSTER routine to identify statistical differences among clusters (Clarke \& Gorley 2006).

\section{RESULTS}

\section{SAV spatial pattern metrics}

In Zone 1, SAV dominant and SAV sparse classes covered $68.9 \%\left(15.0 \mathrm{~km}^{2}\right)$ and $30.7 \%\left(6.7 \mathrm{~km}^{2}\right)$ of the seascape, respectively (Fig. 1b). In Zone 2, the SAV dominant class covered $66.0 \%\left(11.3 \mathrm{~km}^{2}\right)$ and the SAV sparse class covered $33.8 \%\left(5.8 \mathrm{~km}^{2}\right)$ of the seascape (Fig. 1c). Based on the SAV dominant class, spatial pattern metrics showed significant differences between buffers, with some degree of overlap indicated by a small global $\mathrm{R}$ value (ANOSIM test, $\mathrm{R}<0.2$, $\mathrm{p}<0.001$ ). ANOSIM pairwise tests indicated that the $200 \mathrm{~m}$ buffer was the spatial extent where significant dissimilarities in spatial pattern metrics between buffers and zones were observed (illustrated by MDS, CLUSTER; Fig. 3). Differences among buffers (Fig. 3) and zones (Fig. 3a) disappeared when larger distances (and larger buffers) were evaluated. Based on these results, the $200 \mathrm{~m}$ buffer was selected for all subsequent analyses. The 45 sampling sites used to evaluate spatial pattern metrics at the $200 \mathrm{~m}$ buffer scale clustered into 7 groups (CLUSTER; Fig. 4). Groups B and C, and groups $\mathrm{F}$ and $\mathrm{G}$ were joined together based on their similarities (Fig. 4).

Based on the value distributions of the ZLAND, MPS, PDENS, and DLFD, the groups identified in the CLUSTER analysis were further classified into 2 distinct classes (Fig. 5). The groups of sites identified in Fig. 4 were classified as either fragmented SAV seascape (FSS) or continuous SAV seascape (CSS) structures. Groups A, D, and E were classified as CSS, and groups $B$ and $C$, and $F$ and $G$ as FSS. The latter (B, C, F, and G) had, on average, the lowest proportion of the seascape dominated by SAV (low ZLAND values), and presented high densities of smaller SAV patches (higher PDENS) with complex shapes and boundaries (higher DLFD; Fig. 5). Sites with a CSS structure had a higher portion of the seascape occupied by SAV dominant patches (Fig. 5). The low patch density values and high mean patch size values indicate that these groups were characterized mainly by large, continuous SAV patches with simple boundaries (i.e. less convoluted boundaries). Differences in the spatial pattern metrics between CSS and FSS groups were statistically significant (1-way ANOVA, p < 0.01; Fig. 5). 


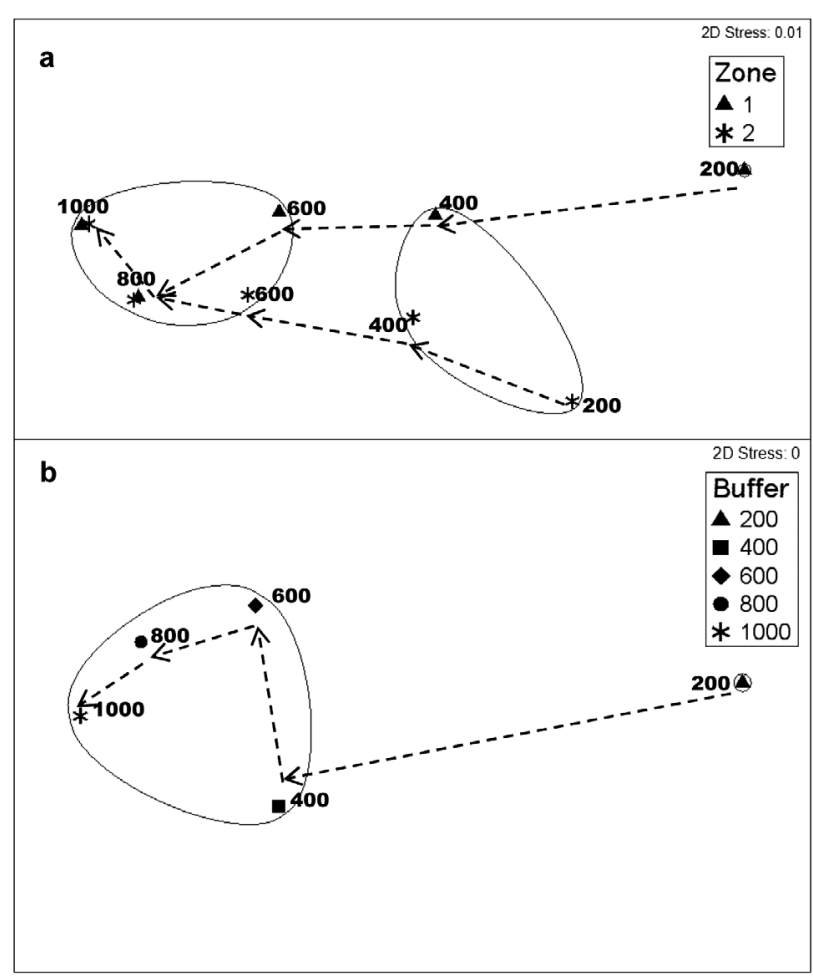

Fig. 3. Multi-dimensional scaling (MDS) plots of the mean spatial pattern metrics in (a) Zones 1 and 2 by distance-toshore buffers, and (b) by buffers. The length of the dashed arrows is proportional to the level of dissimilarity. Contours represent the highest resemblance level (Euclidean distance) from a simple agglomerative hierarchical clustering. The highest submerged aquatic vegetation seascape metrics dissimilarity between buffers and zones occurred at the $200 \mathrm{~m}$ buffer. Stress values represent the measure goodness of fit of the MDS plot

\section{Seascape structure and salinity patterns}

To evaluate the relationship between seascape structure and salinity patterns, we explored (1) the distance between the location of each site and the mouth of freshwater canals; and (2) the mean salinity and salinity variability (i.e. standard deviation) at each location obtained from the Biscayne Bay Hydrodynamic model (Wang et al. 2003) for the 2 yr prior (2004-2005) to the field surveys conducted for this study.

The sites identified as CSS and FSS were not distributed randomly along the shoreline (Fig. 6a). The groups classified as FSS (groups B, C, F, and G) were significantly closer (i.e. shorter mean distance) to the mouth of freshwater canals than the groups classified as CSS (groups A, D, E; 1-way ANOVA, p < 0.05; Fig. 6d). A higher proportion of the sites described as having FSS (19 of 28) were located in areas with a higher concentration of canals (6 canals discharge in Zone 2 compared to only 2 in Zone 1). In contrast, groups with CSS structures (11 of 17) were in areas with lower concen- trations of canals (Fig. 6a,d). Moreover, the FSS groups within Zone 1 were only found adjacent to the 2 canals in this area.

Based on the output of the salinity model, the groups classified as CSS had statistically higher mean salinity and lower salinity variability compared to sites classified as FSS that had lower mean salinity and wider salinity fluctuations (1-way ANOVA, p < 0.05; Fig. 6e,f).

\section{DISCUSSION}

Two classes of SAV patches, SAV dominant (>30\% benthic cover) and SAV sparse (<30\% cover), were delineated within the nearshore habitats of the study area using object-based classification of aerial photographs. Moreover, the multi-scale seascape approach used here identified the $200 \mathrm{~m}$ buffer extension as the scale at which SAV seascape characteristics differed among sites. The clustering of SAV seascape characteristics within this scale revealed 2 main SAV seascape structures: continuous SAV seascape (CSS) and fragmented SAV seascape (FSS). FSS, defined here as habitats with low SAV coverage, large numbers of small patches, and higher patch shape complexity, were prevalent in areas of Biscayne Bay where point sources of fresh water discharged from water management canals create environments with low and variable salinity. CSS were found mainly in areas of the bay removed from canalbased freshwater discharges. Thus, this study indicates that water management practices that regulate freshwater discharges into littoral areas of coastal lagoons may have structural impacts on the SAV seascape structures within the area of influence of freshwater pulses. This finding extends previous research that has shown that SAV species' distributions and abundances are highly influenced by their salinity tolerances (Montague \& Ley 1993, Fourqurean et al. 2003, Lirman \& Cropper 2003, Lirman et al. 2008a,b, Herbert \& Fourqurean 2009). Moreover, these findings are consistent with those reported by Bell et al. (1999, 2007), who showed that losses in productivity and biomass are associated with the formation and persistence of fragmented areas and gaps within the SAV seascape.

Studies that have used remote sensing to assess SAV spatial dynamics have often only considered SAV coverage and change patterns over a single, broad scale (Ferguson \& Korfmacher 1997, Cole et al. 2002, Hernandez-Cruz et al. 2006, Dekker et al. 2007, Moore et al. 2009), and have rarely applied landscape theory or metrics (Bell et al. 2007). In landscape ecology, there is a consensus that there is not a single, 'best scale' for research and that overemphasis on either very small or very large scales is not recommended (Kent 2005). Thus, to have a robust understanding of spatial pat- 


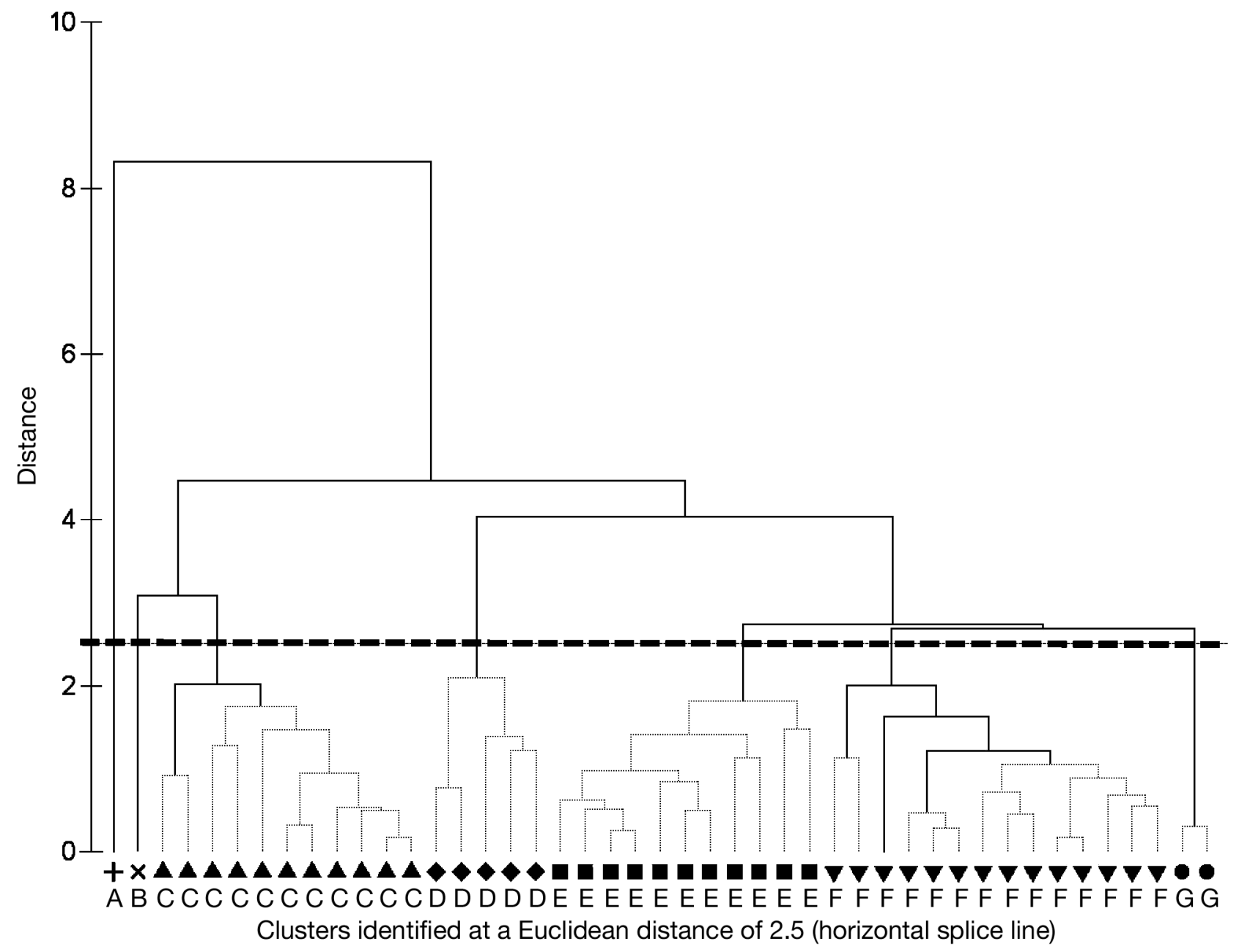

Fig. 4. Clustering of sites based on seascape characteristics measured within the $200 \mathrm{~m}$ buffer. Clustering labels defined at the Euclidean distance 2.5 (black horizontal dashed line). Dotted lines indicate where the SIMPROF test found no statistical evidence of sub-structure within these groups

terns within landscapes, it is important to quantify habitat spatial heterogeneity explicitly at multiple scales (Levin 1992, Wu et al. 2002, Shen et al. 2004, Kendrick et al. 2008). Factors and processes important at 1 scale are frequently not important or predictive at another scale, and information is often lost if spatial data are not considered at multiple scales (Turner et al. 1989). When only the total aerial coverage of SAV dominant patches was compared between the 2 zones surveyed in Biscayne Bay, no significant differences were detected. However, when a multi-scale approach was used and spatial pattern metrics were evaluated at increasing distances from shore and buffer sizes, the $200 \mathrm{~m}$ buffer was identified as the scale at which SAV seascape characteristics differed significantly among salinity zones. Thus, this study highlights the significance for the monitoring of SAV spatial distribution to incorporate multi-scale approaches to examine the underlying driving processes of SAV spatial patterns.
Spatial pattern metrics are known to be spatially correlated and scale-dependent (Wu 2004), and are also sensitive to changes of scale (Turner et al. 1989, 2001). Accordingly, comparisons of spatial pattern metrics quantified at different scales may reflect scale-related errors or effects rather than true differences in landscape patterns (Turner et al. 2001). The spatial pattern metrics selected in this study (i.e. percentage of landscape, fractal dimension, patch size, patch density) are known to be robust and stable across multiple scales (e.g. Saura \& Martinez-Millan, 2001). Thus, the SAV seascape patterns described for Biscayne Bay can be considered a result of the distribution and spatial arrangement of driving factors and not an artifact of scaling effects.

Sublethal stressors known to influence the structure of SAV seascapes may alter vital processes such as photosynthesis, growth, and reproduction. The impacts of these factors (e.g. nutrients, depth, light, and 

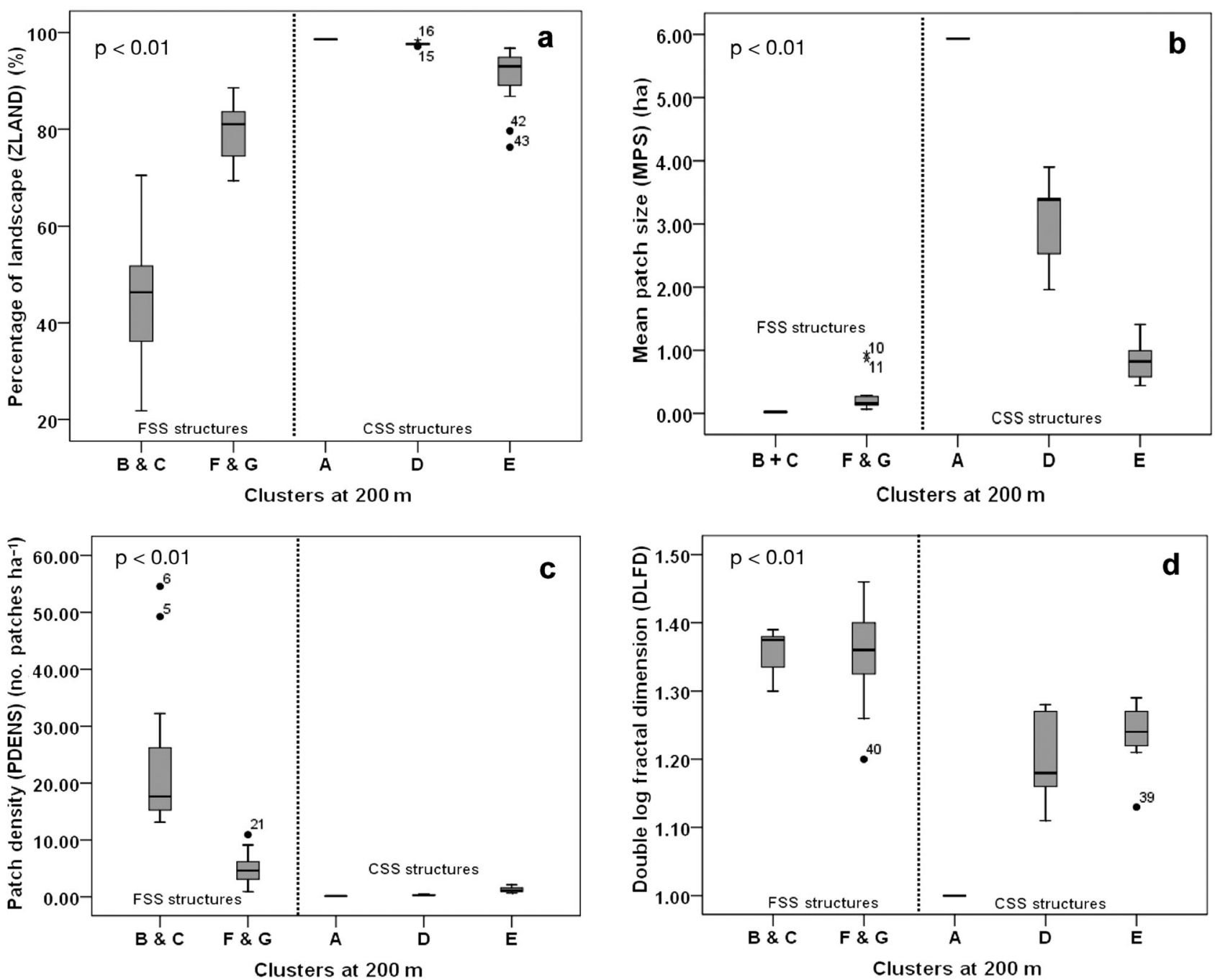

Fig. 5. Value distribution of (a) proportion of the landscape (ZLAND), (b) mean patch size (MPS), (c) patch density (PDENS), and (d) double log fractal dimension (DFLD) within the groups identified in the cluster analysis (Fig. 4). Based on these 4 spatial pattern metrics, these groups were classified as continuous submerged aquatic vegetation (SAV) seascape (CSS), and fragmented SAV seascape (FSS) structures. The dotted line in the box plots separates the groups classified as CSS and FSS. The differences between the spatial pattern metrics within CSS and FSS were statistically significant (1-way analysis of variance, $p<0.01)$. Horizontal lines: median; boxes: 25th-75th percentile; whiskers: data range; black dots and asterisks: outliers (with site number)

salinity zonation, space competition) are commonly species-specific and are based on the physiological tolerances or requirements of species and assemblages (Frederiksen et al. 2004, Boström et al. 2006, Bell et al. 2007). While SAV seascape characteristics and salinity patterns are clearly spatially correlated in western Biscayne Bay, the formation and persistence of gaps and the shrinkage or removal of SAV patches can be potentially associated with other driving variables such as temperature, dissolved oxygen (DO), currents, and nutrient availability. However, Lirman \& Serafy $(2008$, 2009) showed that in the shallow environments of nearshore Biscayne Bay, no differences in depth, light penetration, temperature, and DO are found between the 2 areas compared in this study in the dry season, when the aerial imagery for this study was collected. A lack of spatial patterns in DO, temperature, and turbidity between the zones examined in this study was also reported by Caccia \& Boyer (2005). Sediment depth, also known to influence the distribution and abundance of seagrasses (Zieman et al. 1989), exceeded $25 \mathrm{~cm}$ throughout the study area (Lirman et al. 2003), providing ranges suitable for seagrass meadow formation (Zieman 1972).

Nutrients in the water column were not measured here, but previous studies have shown correlations between freshwater and nutrient inputs into this P-limited lagoon (Fourqurean \& Robblee 1999, Four- 

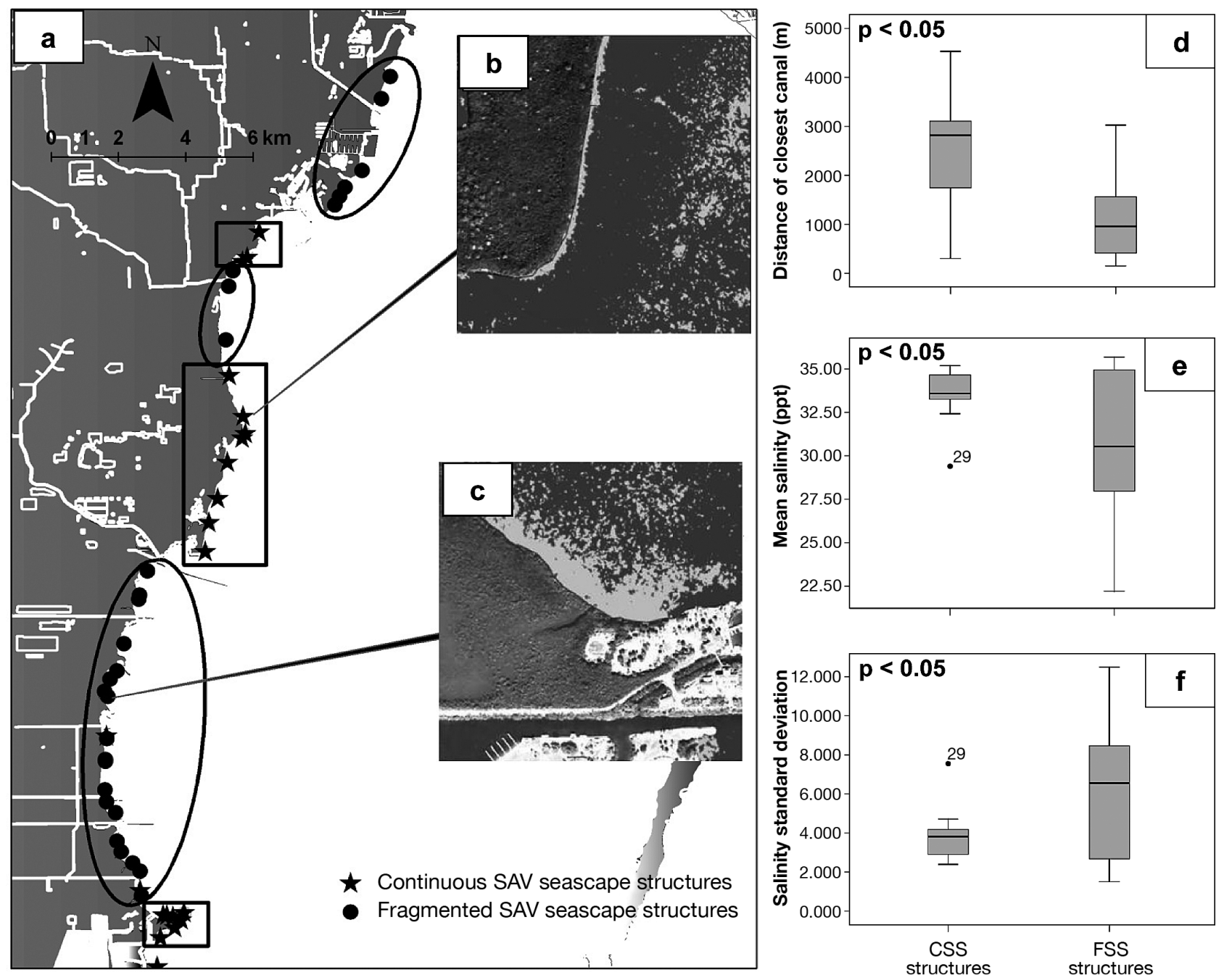

Fig. 6. (a) Spatial distribution of sites identified in the clustering analysis (Fig. 3) based on seascape characteristics measured within the $200 \mathrm{~m}$ buffer. Groups with continuous submerged aquatic vegetation (SAV) seascape (CSS) structures are represented by black stars, and groups with fragmented SAV seascape (FSS) structures are represented by black filled circles. Areas with higher proportions of groups with FSS structures are bordered with black ovals, and areas with higher proportions of groups with CSS structures are bordered with black rectangles. Canals and major streams are illustrated with white lines. Illustration of (b) CSS structure and (c) FSS structures. Boxplots (see Fig. 5 for boxplot limits) illustrate the values distribution of (d) distance of the closest canal, (e) mean salinity, and (f) salinity standard deviation within the clusters classified as FSS and CSS (1-way analysis of variance, $\mathrm{p}<0.05$ )

qurean et al. 2003, Biber et al. 2004, Caccia \& Boyer 2005, 2007). Thus, nutrient availability, together with freshwater pulses, may play a synergistic role in determining SAV patch structure in the study area. Nutrient loadings have been linked to direct and indirect negative effects on the productivity and spatial assemblages of SAV species (Orth et al. 2006, Waycott et al. 2009). For example, light availability can be reduced by phytoplankton blooms and suspended organic matter associated with high nutrient loads (Fourqurean \& Robblee 1999, Duarte 2002, Fourqurean et al. 2003). In addition, increased nutrients have been linked to high epiphyte and drift algae biomass that can control sea- grass biomass and distribution through light limitation and competition for nutrients (Holmquist 1997, Biber et al. 2004, van Tussenbroek et al. 2007). Until the separate (and potentially synergistic) impacts of salinity and nutrient availability on SAV seascape structure have been experimentally determined, observed patterns in Biscayne Bay cannot be causally linked to one or the other factor.

Hydrodynamic forces have been suggested as potentially more important structuring features in the SAV seascape than other driving variables that control the physiological responses of macrophytes (Bell et al. 1999). Factors such as tidal currents and wave expo- 
sure have been shown to directly influence SAV patch size, shape, and distribution (Robbins \& Bell 2000, Bell et al. 2007). For example, Fonseca \& Bell (1998) reported that SAV seascape characteristics such as percent cover and seagrass bed perimeter-to-area ratio declined with increasing mechanical disturbance produced by waves and tidal currents. Frederiksen et al. (2004) found that Zostera marina formed continuous meadows only in sheltered areas. Acute disturbances such as storms have also been found to be dominant factors structuring and maintaining seascape heterogeneity, and transitions between vegetated and barren areas (Ramage \& Schiel 1999, Robbins \& Bell 2000). Hydrodynamic forcing is clearly a key structuring factor on SAV seascapes, but there is a low likelihood that mechanical disturbances are a major driver within our study area, especially at the $200 \mathrm{~m}$ scale (buffer with highest heterogeneity in SAV seascape structure). The zones surveyed here are of shallow and fairly uniform depth and are sheltered by a mangrove coastline. Finally, while storms and hurricanes have impacted the study area historically (Manzello et al. 2007), the short distance separating the 2 areas assessed is clearly smaller than the area of influence of any single storm.

Even if the role of mechanical factors as a structuring force at the scale of our study is likely minor, the characteristics of the SAV patches may indeed influence the susceptibility of the SAV seascape to future storm events. Previous studies have identified a critical patch size $\left(<25 \mathrm{~m}^{2}\right.$ for patches of the temperate seagrasses Zostera spp.) beyond which the likelihood of patch mortality decreases significantly (Olesen \& SandJensen 1994, Ramage \& Schiel 1999, Kendrick et al. 2005). Thus, continuous SAV seascapes may be more resistant and resilient to physical disturbances than fragmented SAV seascapes since the homogeneous root-rhizome matrix stabilizes the sediment and less patch edge is exposed to damage from waves or currents (Ramage \& Schiel 1999, Frederiksen et al. 2004). Large patches have higher potential for resource accumulation to support patch growth (Kendrick et al. 2005), and the high mortality associated with small SAV patches could be linked to lack of mutual protection and firm anchorage leading to higher susceptibility to physical disturbances and nutrient stress (Duarte et al. 2007). Within this context, future changes in salinity patterns caused by restoration may have longterm negative impacts in terms of SAV patch persistence if further seascape fragmentation takes place.

While the focus of the present study was the spatial and structural characteristics of SAV seascapes and spatial correlations with salinity patterns, the potential for these impacts to propagate up the food chain and affect higher trophic levels deserves further consideration. The use of SAV habitat patches as transient and permanent habitat by fish and invertebrates highlights the need to better understand how the value of ecological services provided by SAV habitats may change with modification on the SAV seascape structure. Biscayne Bay has one of the longest and most detailed records of mangrove fish communities (Serafy et al. 2003, Faunce \& Serafy 2006), providing a unique opportunity to assess how distinct SAV seascape patterns influence the abundance and diversity of fish communities, and the connectivity and synergistic functions of multiple critical habitats in heterogeneous seascape. In the near future, this spatially explicit fish dataset will be related to the SAV seascape patterns recorded in this study to ascertain the role of seascape structure on fish habitat utilization patterns.

In summary, using a multi-scale seascape approach adapted from landscape ecology, the seascape structure of SAV communities in Biscayne Bay (Florida, USA), was found to be spatially correlated with areas of pulsed freshwater releases into littoral areas. SAV communities in the area of influence of freshwater releases had structural characteristics consistent with fragmented habitats, including high density of small patches and a higher proportion of sparse SAV patches. While patch structure of SAV seascapes can be driven by a number of biological and physical factors, the spatial data collected in this study area indicated that salinity patterns (and correlated nutrient availability) are likely the main factor influencing the observed SAV spatial patterns. Results presented here show that previously reported impacts of salinity at the individual and species levels scale up to a landscape level within this shallow coastal system. Due to the implementation of a multi-scale approach, these spatial patterns were discerned and related to potential processes, which otherwise could be precluded and masked by broad and single scale quantification of aerial extent of SAV patches. Coastal and estuarine monitoring and management at the ecosystem level should apply multi-scale and multidisciplinary methodologies not only to understand spatial features of essential marine habitats, but also to understand the functional linkages between habitats in a heterogeneous seascape, and the abundance, movement, and growth of ecological and economically important marine species.

Acknowledgements. Funding for this study was provided by NOAA's National Geodetic Survey (D.L.), the US Department of the Interior's Critical Ecosystem Studies Initiative (D.L.), the RECOVER Monitoring and Assessment Program (MAP; D.L. and J.E.S.), the Army Corps of Engineers (D.L. and J.E.S.), the McKnight Doctoral Fellowship Program (R.O.S.), and NOAA's Living Marine Resources Cooperative Science Center (R.O.S.). The manuscript benefited from comments by S. Purkis, E. Hochberg, and S. Pittman. 


\section{LITERATURE CITED}

Alleman RW (1995) An update to the surface water improvement and management plan for Biscayne Bay. South Florida Water Management District, West Palm Beach, FL

Beck MW, Heck KL, Able KW, Childers DL and others (2001) The identification, conservation, and management of estuarine and marine nurseries for fish and invertebrates. Bioscience 51:633-641

Beets J, Muehlstein L, Haught K, Schmitges H (2003) Habitat connectivity in coastal environments: patterns and movements of Caribbean coral reef fishes with emphasis on bluestriped grunt, Haemulon sciurus. Gulf Caribb Res 14: 29-42

Bell SS, Robbins BD, Jensen SL (1999) Gap dynamics in a seagrass landscape. Ecosystems 2:493-504

Bell SS, Fonseca MS, Stafford NB (2007) Seagrass ecology: new contributions from a landscape perspective. In: Larkum AWD, Orth RJ, Duarte CM (eds) Seagrasses: biology, ecology and conservation. Springer, Dordrecht, p 625-645

Biber PD, Harwell MA, Cropper WP (2004) Modeling the dynamics of three functional groups of macroalgae in tropical seagrass habitats. Ecol Model 175:25-54

Boström C, Jackson EL, Simenstad CA (2006) Seagrass landscapes and their effects on associated fauna: a review. Estuar Coast Shelf Sci 68:383-403

Botequilha A, Miller J, Ahern J, McGarigal K (2006) Measuring landscapes: a planner's handbook. Island Press, Washington, DC

Browder JA, Ogden JC (1999) The natural South Florida system II: predrainage ecology. Urban Ecosyst 3:245-277

Caccia VG, Boyer JN (2005) Spatial patterning of water quality in Biscayne Bay, Florida as a function of land use and water management. Mar Pollut Bull 50:1416-1429

Caccia VG, Boyer JN (2007) A nutrient loading budget for Biscayne Bay, Florida. Mar Pollut Bull 54:994-1008

Clarke KR, Gorley RN (2006) PRIMER v6: user manual/ tutorial. Primer-E, Plymouth

Clarke KR, Warwick RM (2001) Change in marine communities: an approach to statistical analysis and interpretation. Primer-E, Plymouth

Cole KB, Carter DB, Schonder C, Finkbeiner M, Seaman R (2002) Finding the green under the sea: the Rehoboth Bay Ulva identification project. In: Wright D (ed) Undersea with GIS. ESRI Press, Redlands, CA, p 85-104

Connolly RM, Hindell JS (2006) Review of nekton patterns and ecological processes in seagrass landscapes. Estuar Coast Shelf Sci 68:433-444

Costanza R, D'Arge R, De Groot R, Farber S and others (1997) The value of the world's ecosystem services and natural capital. Nature 387:253-260

Davis SM, Ogden JC (1994) Toward ecosystem restoration. In: Davis SM, Ogden JC (eds) Everglades. The ecosystem and its restoration. St. Lucie Press, Delray Beach, FL, p 769-797

Davis S, Lirman D, Wozniak J (2009) Nitrogen and phosphorus exchange among tropical coastal ecosystems. In: Nagelkerken I (ed) Ecological connectivity among tropical coastal ecosystems. Springer, Dordrecht, p 9-43

Dekker A, Brando V, Anstee J, Fyfe S, Malthus T, Karpouzi E (2007) Remote sensing of seagrass ecosystems: use of spaceborne and airborne sensors. In: Larkum AWD, Orth RJ, Duarte CM (eds) Seagrasses: biology, ecology and conservation. Springer, Dordrecht, p 347-359

Diaz GA (2001) Population dynamics and assessment of pink shrimp (Farfantepenaeus duorarum) in subtropical nurs- ery grounds. PhD dissertation. University of Miami, Coral Gables, FL

Duarte CM (2002) The future of seagrass meadows. Environ Conserv 29:192-206

Duarte CM, Fourqurean JW, Krause-Jensen D, Olesen B (2007) Dynamics of seagrass stability and change. In: Larkum AWD, Orth RJ, Duarte CM (eds) Seagrasses: biology, ecology and conservation. Springer, Dordrecht, p 271-294

Faunce CH, Serafy JE (2006) Mangroves as fish habitat: 50 years of field studies. Bull Mar Sci 318:1-18

Faunce CH, Lorenz JJ, Ley JA, Serafy JE (2002) Size structure of gray snapper (Lutjanus griseus) within a mangrove 'no take' sanctuary. Bull Mar Sci 70:211-216

Ferguson RL, Korfmacher K (1997) Remote sensing and GIS analysis of seagrass meadows in North Carolina, USA. Aquat Bot 58:241-258

Fonseca MS, Bell SS (1998) Influence of physical setting on seagrass landscapes near Beaufort, North Carolina, USA. Mar Ecol Prog Ser 171:109-121

Fourqurean JW, Robblee MB (1999) Florida Bay: a history of recent ecological changes. Estuaries 22:345-357

> Fourqurean JW, Boyer JH, Durako MJ, Hefty LN, Peterson BJ (2003) Forecasting responses of seagrass distributions to changing water quality using monitoring data. Ecol Appl 13:474-489

> Frederiksen M, Krause-Jensen D, Holmer M, Laursen S (2004) Spatial and temporal variation in eelgrass (Zostera marina) landscapes: influence of physical setting. Aquat Bot 78:147-165

Grober-Dunsmore R, Fraze TK, Beets J, Lindberg WJ, Zwick P, Funicelli NA (2008) Influence of landscape structure on reef fish assemblages. Landscape Ecol 23:37-53

> Herbert DA, Fourqurean JW (2009) Phosphorus availability and salinity control productivity and demography of the seagrass Thalassia testudinum in Florida Bay. Estuaries Coasts 32:188-201

Hernandez-Cruz LR, Purkis SJ, Riegl BM (2006) Documenting decadal spatial changes in seagrass and Acropora palmata cover by aerial photography analysis in Vieques, Puerto Rico: 1937-2000. Bull Mar Sci 79:401-414

Holmquist JG (1997) Disturbance and gap formation in a marine benthic mosaic: influence of shifting macroalgal patches on seagrass structure and mobile invertebrates. Mar Ecol Prog Ser 158:121-130

- Hovel KA, Regan HM (2008) Using an individual-based model to examine the roles of habitat fragmentation and behavior on predator-prey relationships in seagrass landscapes. Landscape Ecol 23:75-89

Irlandi EA, Crawford MK (1997) Habitat linkages: the effect of intertidal saltmarshes and adjacent subtidal habitats on abundance, movement, and growth of an estuarine fish. Oecologia 110:222-230

Jelbart JE, Ross PM, Conolly RM (2007) Fish assemblages in seagrass beds are influenced by the proximity of mangrove forests. Mar Biol 150:993-1002

Kelly M, Tuxen K (2009) Remote sensing support for tidal wetland vegetation research and management. In: Yang X (ed) Remote sensing and geospatial technologies for coastal ecosystem assessment and management. Springer, Berlin, p 341-363

Kendall MS (2005) A method for investigating seascape ecology of reef fish. Proc Gulf Caribb Fish Inst 56:355-366

> Kendrick GA, Duarte CM, Marbà N (2005) Clonality in seagrass, emergent properties and seagrass landscapes. Mar Ecol Prog Ser 290:291-296

Kendrick GA, Holmes KW, Van Niel K (2008) Multi-scale 
spatial patterns of three seagrass species with different growth dynamics. Ecography 31:191-200

Kent M (2005) Biogeography and macroecology. Prog Phys Geogr 29:256-264

Levin SA (1992) The problem of pattern and scale in ecology. Ecology 73:1943-1967

Lirman D, Cropper WP (2003) The influence of salinity on seagrass growth, survivorship, and distribution with Biscayne Bay, Florida: field, experimental, and modeling studies. Estuaries 26:131-141

Lirman D, Serafy JE (2008) Documenting Everglades restoration impacts on Biscayne Bay's shallowest benthic habitats. First Annual Report. CERP Monitoring and Assessment Plan Component: Activity Number 3.2.3.3. Miami, FL

Lirman D, Serafy JE (2009) Documenting Everglades restoration impacts on Biscayne Bay's shallowest benthic habitats. Second Annual Report. CERP Monitoring and Assessment Plan Component: Activity Number 3.2.3.3. Miami, FL

Lirman D, Orlando B, Macia S, Manzello D, Kaufman L, Biber P, Jones T (2003) Coral communities of Biscayne Bay, Florida and adjacent offshore areas: diversity, abundance, distribution, and environmental correlates. Aquat Conserv 13:121-135

Lirman D, Deangelo G, Serafy JE, Hazra A, Hazra DS, Brown A (2008a) Geospatial video monitoring of nearshore benthic habitats of western Biscayne Bay (Florida) using the Shallow-Water Positioning System (SWaPS). J Coast Res 24:135-145

Lirman D, Deangelo G, Serafy JE, Hazra A and others (2008b) Seasonal changes in the abundance and distribution of submerged aquatic vegetation in a highly managed coastal lagoon. Hydrobiologia 596:105-120

Manzello DP, Brandt M, Smith TB, Lirman D, Hendee JC, Nemeth RS (2007) Hurricane-associated cooling benefits bleached corals. Proc Natl Acad Sci USA 104:12035-12039

McGarigal K, Cushman SA, Neel MC, Ene E (2002) FRAGSTATS: spatial pattern analysis program for categorical maps. University of Massachusetts, Amherst, MA. Available at www.umass.edu/landeco/research/fragstats/ fragstats.html

Mellin C, Andrefouet S, Ponton D (2007) Spatial predictability of juvenile fish species richness and abundance in a coral reef environment. Coral Reefs 26:895-907

Mellin C, Andrefouet S, Kulbicki M, Dalleau M, Vigliola L (2009) Remote sensing and fish-habitat relationships in coral reef ecosystems: review and pathways for systematic multi-scale hierarchical research. Mar Pollut Bull 58: 11-19

> Montague CL, Ley J (1993) A possible effect of salinity fluctuation on abundance of benthic vegetation and associated fauna in northeastern Florida Bay. Estuaries 16:703-717

Moore KA, Orth RJ, Wilcox DJ (2009) Assessment of the abundance of submerged aquatic vegetation (SAV) communities in the Chesapeake Bay and its use in SAV management. In: Yang X (ed) Remote sensing and geospatial technologies for coastal ecosystem assessment and management. Springer, Berlin, p 233-258

Mumby PJ, Harbourne AR (1999) Development of a systematic classification scheme of marine habitats to facilitate regional management and mapping of Caribbean coral reefs. Biol Conserv 88:155-163

> Nagelkerken I, van der Velde G (2004a) Are Caribbean mangroves important feeding grounds for juvenile reef fish from adjacent seagrass beds? Mar Ecol Prog Ser 274: 143-151

Nagelkerken I, van der Velde G (2004b) Relative importance of interlinked mangroves and seagrass beds as feeding habitats for juvenile reef fish on a Caribbean island. Mar Ecol Prog Ser 274:153-159

> Nagelkerken I, Kleijnen S, van den Brand RACJ, Cocheret de la Moriniere E, van der Velde G (2001) Dependence of Caribbean reef fishes on mangroves and seagrass beds as nursery habitats: a comparison of fish faunas between bays with and without mangroves/seagrass beds. Mar Ecol Prog Ser 214:225-235

Olesen B, Sand-Jensen K (1994) Patch dynamics of eelgrass Zostera marina. Mar Ecol Prog Ser 106:147-156

Orth RJ, Carruthers TJB, Dennison WC, Duarte CM and others (2006) A global crisis for seagrass ecosystems. Bioscience 56:987-995

Parrish JD (1989) Fish communities of interacting shallowwater habitats in tropical oceanic regions. Mar Ecol Prog Ser 58:143-160

Pittman SJ, McAlpine CA, Pittman KM (2004) Linking fish and prawns to their environment: a hierarchical landscape approach. Mar Ecol Prog Ser 283:233-254

Pittman SJ, Caldow C, Hile SD, Monaco ME (2007) Using seascape types to explain the spatial patterns of fish in the mangroves of SW Puerto Rico. Mar Ecol Prog Ser 348: $273-284$

Ramage DL, Schiel DR (1999) Patch dynamics and response to disturbance of the seagrass Zostera novazelandica on intertidal platforms in southern New Zealand. Mar Ecol Prog Ser 189:275-288

Rempel R (2008) Patch Analyst v4. Centre for Northern Forest Ecosystem Research, Lakehead University, Thunder Bay, $\mathrm{ON}$

Robbins B, Bell SS (1994) Seagrass landscapes: a terrestrial approach to the marine subtidal environment. Trends Ecol Evol 9:301-304

Robbins B, Bell SS (2000) Dynamics of subtidal seagrass landscape: seasonal and annual change in relation to water depth. Ecology 81:1193-1205

Saura S, Martinez-Millan J (2001) Sensitivity of landscape pattern metrics to map spatial extent. Photogramm Eng Remote Sens 67:1027-1036

> Serafy JE, Lindeman KC, Hopkins TE, Ault JS (1997) Effects of freshwater canal discharge on fish assemblages in a subtropical bay: field and laboratory observations. Mar Ecol Prog Ser 160:161-172

Serafy JE, Faunce CH, Lorenz JJ (2003) Mangrove shoreline fishes of Biscayne Bay, Florida. Bull Mar Sci 72:161-180

Shen W, Jenerette GD, Wu J, Gardner RH (2004) Evaluating empirical scaling relations of pattern metrics with simulated landscapes. Ecography 27:459-469

Stalker JC, Price RM, Swart PK (2009) Determining spatial and temporal inputs of freshwater, including submarine groundwater discharge, to a subtropical estuary using geochemical tracers, Biscayne Bay, South Florida. Estuaries Coasts 32:694-708

> Trzcinski MK, Fahrig L, Merriam G (1999) Independent effects of forest cover and fragmentation on the distribution of forest breeding birds. Ecol Appl 9:586-593

- Turner MG, O'Neill RV, Gardner RH, Milne BT (1989) Effects of changing spatial scale on the analysis of landscape pattern. Landscape Ecol 3:153-162

Turner MG, Gardner RH, O'Neill RV (2001) Landscape ecology in theory and practice: pattern and process. Springer, New York, NY

van Tussenbroek BI, Vonk JA, Stapel J, Erftemeijer PLA, Middelburg JJ, Zieman JC (2007) The biology of Thalassia: paradigms and recent advances in research. In: Larkum AWD, Orth RJ, Duarte CM (eds) Seagrasses: biology, eco- 
logy and conservation. Springer, Dordrecht, p 409-439

Wang JD, Luo J, Ault JS (2003) Flows, salinity and some implications for larval transport in south Biscayne Bay, Florida. Bull Mar Sci 72:695-723

- Waycott M, Duarte CM, Carruthers TJB, Orth RJ and others (2009) Accelerating loss of seagrasses across the globe threatens coastal ecosystems. Proc Natl Acad Sci USA 106: $12377-12381$

$>$ Wu J (2004) Effects of changing scale on landscape pattern analysis: scaling relations. Landscape Ecol 19:125-138

Submitted: May 30, 2010; Accepted: December 14, 2010
Wu J, Shen W, Sun W, Tueller PT (2002) Empirical patterns of the effects of changing scale on landscape metrics. Landscape Ecol 17:761-782

Zieman JC (1972) Origin of circular beds of Thalassia (Spermatophyta: Hydrocharitaceae) in south Biscayne Bay, Florida, and their relationship to mangrove hammocks. Bull Mar Sci 22:559-574

Zieman JC, Fourqurean JW, Iverson RL (1989) Distribution, abundance and productivity of seagrasses and macroalgae in Florida Bay. Bull Mar Sci 44:292-311

Proofs received from author(s): April 4, 2011 